\title{
A Newcomer's Guide to Life Cycle Assessment - Baselines and Boundaries
}

\section{RGTW Working Paper Number 3, 2015}

Alfred Gathorne-Hardy ${ }^{1}$ Alfred Gathorne-Hardy <alfred.gathorne-hardy@some.ox.ac.uk>

\section{Introduction}

Life cycle assessment (LCA) aims to understand the environmental impact of a product or service (termed a functional unit) over its entire life cycle - using 'standard methodologies'. The concept of LCA is simple - determine all the processes and products needed to produce the functional unit, measure the environmental impacts associated with each, and sum these up. But the reality is more complicated - for a range of reasons, two of which will be focused on in this paper.

The 'boundaries' in LCA refer to what is or is not included within the assessment. The production history of a functional unit is rarely a simple chain of inputs and outputs. Instead the final product, and all intermediate stages, are better portrayed as parts within a wider web - analogous to considering a food chain as we are taught in primary school, compared to the complicated reality of a food web, see Figure 1 below. When building an LCA, the boundary question concerns the bits of this web that should be included.

\footnotetext{
${ }^{1}$ Prepared in dialogue with Rebecca White and Barbara Harriss-White
} 


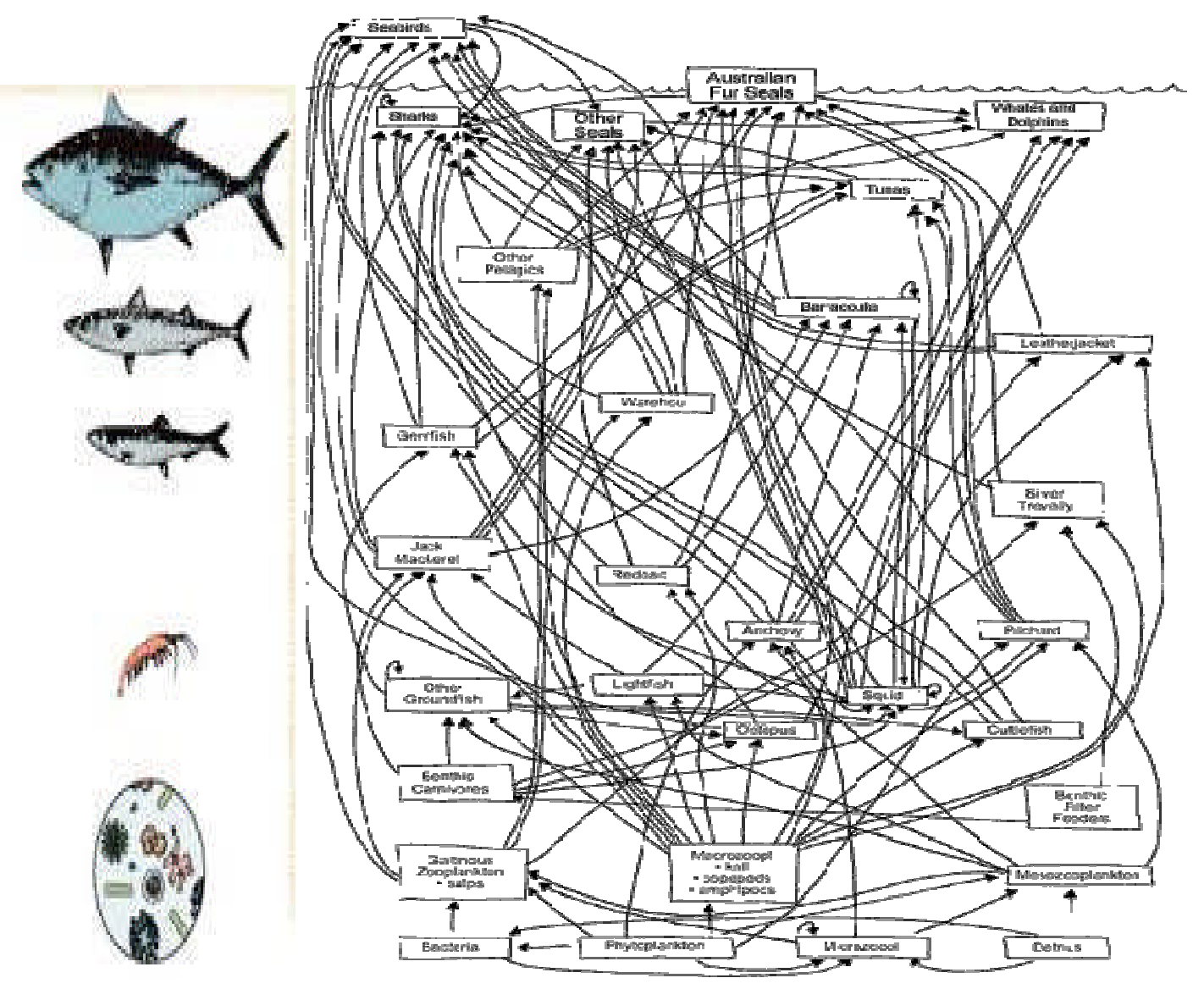

Figure 1. A simplified marine food chain, compared to a more realistic marine food web

Source: https://myweb.rollins.edu/jsiry/marine foodwebs.jpeg

'Baselines' are the counterfactuals against which we compare the selected case - for example the fuel, food, clothing and building material that would otherwise have been used if the functional unit were not. The choice of baselines is important as it is against them that the functional unit is compared. If an especially poorly rated alternative is chosen as a counterfactual, the functional unit will appear unrepresentatively 'good', and vice versa. So careful justification of the choice of baselines and boundaries in life cycle assessment is essential in order to avoid misleading results.

Baselines and boundaries can be simple to identify, but often surprisingly complicated problems to solve. When reading any LCA, or listening to anyone promoting one technology/product/concept compared with others, consider what they are saying from the perspective of baselines and boundaries. Have they considered them, and if so, have they made the right decisions? The aim of this paper is to introduce the concepts, and then go into some more detail about how different types of baseline and boundary problems can be solved. It makes heavy use of bioenergy LCA literature, due to its related nature (both biofuels and rice have to deal with the problems of agriculture and land use) and due to the funding history of this work, but where possible the problems discussed are related back to rice production. 


\section{Boundaries.}

Where should LCA boundaries be drawn? For practical reasons, the boundaries should be as tight as possible, as there is no benefit in collecting/measuring unnecessary information. But for perfect accuracy all products and flows should be included. So how should the trade-off between practicality and accuracy be determined in a methodical fashion?

LCA principles are set out in ISO 14040, with key additional guidelines for GHG LCA developed by PAS2050:2011 (PAS 2050:2011, 2011). PAS 2050 states that boundaries should include "all emissions and removals within the system boundary that have the potential to make a material contribution". In turn this is defined as the contribution from any one source of GHG emission of more than $1 \%$ of the anticipated total GHG emissions, 3.31, PAS 2050:2011 (2011). While PAS 2050 is only concerned with GHG emissions, we might question whether the method and rule be applied to all other measures of an LCA energy use, water used, acidification etc?

ISO 14040 suggests an iterative route for determining system boundaries, but without a specific cut-off point mentioned. Boundaries should initially be established using best available data, and then - using sensitivity analysis - the individual components should be explored, for some to be withdrawn and others that had previously been excluded to be included.

Together these two procedures describe a practical approach to system boundaries, yet in the LCA literature poorly designed system boundaries are abundant. Three specific problems exist: lack of data on deliberately excluded aspects, passive exclusion of components not considered at all, and incorrect assumptions

Deliberately excluded aspects. Many of the excluded processes may have never been assessed, so it is possible to underestimate their actual importance (Suh et al., 2004). For example, in a paper looking at the value of recycled paper compared to virgin paper + incineration, the answer to the question of which is more environmentally friendly was reversed depending upon the boundary location (Merrild et al., 2008). Examples applicable to rice LCAs could include the deliberate exclusion of bovine methane emissions when bullocks are used for transport, or off-site $\mathrm{N}_{2} \mathrm{O}$ emissions from leached nitrogen fertiliser.

Ignored components. In the area of bioenergy LCAs one commonly-ignored component is indirect land use change (ILUC) ${ }^{2}$. This was widely ignored from biofuel LCAs until the issue was brought to major attention by the Gallagher Review (Gallagher, 2008) and then influentially re-iterated in Searchinger et al. (2008). Since then the inclusion of ILUC has been more widespread, but is still widely ignored or misunderstood. A second example is the consideration of biomass as carbon neutral in bioenergy LCA's ${ }^{3}$ (for example Fowles,

\footnotetext{
${ }^{2}$ Indirect land use change is further discussed below under Indirect Effects

${ }^{3}$ Present IPCC recommendations for calculating GHG emissions suggest that energy from biomass is carbon neutral, as that energy is from a short term carbon cycle (ie trees) compared to the long term carbon cycle of fossil fuels.
} 
2007; Gaunt and Lehmann, 2008; Hammond, 2009; Obernbergera, 1998; Roberts et al., 2009; Slade et al., 2009; World Energy Council, 2004). This is an important factor for slowgrowing sources of biomass, where carbon neutrality will only occur once a tree has regrown to the original size of the tree that was combusted. It also ignores the role of bioenergy in increasing the demand for biomass, as bioenergy production uses feedstocks for paper and pulp, forcing these industries to source additional biomass with its possible additional influences on GHG emissions. While recent output, for example by the RSPB (2011), has begun to place this issue into the policy arena, it is still widely ignored in both policy and academic literature.

With respect to rice, both deliberately excluded and ignored components are important. A novel farming process may produce less GHG emissions ha ${ }^{-1}$ or $\mathrm{t}^{-1}$, but if it produces substantially fewer tonnes of rice per hectare then was previously produced the global implications of reduced food production driving indirect land use change need to be understood. Biomass is a key source of energy for producing steam and drying paddy in rice mills, but the emissions associated with this have never (as far as the author can discover) been included in carbon accounting of rice. When rice husk is used as a feedstock then the $\mathrm{CO}_{2}$ can be safely ignored as it was only sequestered in the very recent past, but inefficient boilers are likely to produce methane in addition to $\mathrm{CO}_{2}$ - radically changing the net global warming potential from husk combustion. So ignoring the emissions from biomass combustion can substantially change the net carbon balance.

Incorrect assumptions. Often LCA practitioners find a major, un-fillable gap in their data, and legitimately have to fudge a figure in order to proceed - while this may sound bad practice, avoiding fudging would stall the LCA - and a transparent fudging can be more useful than no data at all. Problems emerge if the fudging is poor; for example if wheat $\mathrm{N}_{2} \mathrm{O}$ emission factors are used in a LCA for rice this would give very misleading results. In the LCA literature, this type of poor assumption can be seen in research assessing the production of PV cells. Key components of the PV cells were made in China and SE Asia, but because it was "not possible" to quantify emissions from these countries it was assumed that they had been fabricated from a European energy supply (Espinosa et al., 2011). The embodied GHG in Chinese electricity is substantially higher than that from Europe (IEA, 2012), making this a poor assumption, with the potential to affect the final results in a significant way.

\section{Baselines}

Baselines are the counterfactuals against which we compare the results for the functional unit of interest. Not all LCA projects are designed for comparison - some aim to understand where and when emissions occur during the manufacture/use of a specific product. But many LCAs deliberately compare different systems, for example organic vs conventional, biofuels versus fossil fuels. 
The complications surrounding baselines are the choice of baselines and the baseline boundaries. If we are interested in the carbon intensity of a specific biofuel for instance, it can be compared to a range of biofuels and the 'worse' the comparator(s), the 'better' the emissions profile of the biofuel being assessed.

In the current project we examine GHG emissions from four different sets of rice production practices, but depending on where the data is collected we may not be able to treat them as perfect baselines, due to uncontrolled variables between the sets of production practices (for example different soil types, different labour arrangements, different depths of ground water tables). If this is the case we can highlight where the different process appear to show different GHG emissions, but no more than that. This is discussed in greater detail in Gathorne-Hardy, 2013; Gathorne-Hardy and Harriss-White, 2013.

Baseline boundaries suffer from the same complications as the main product boundaries, but are often given even less attention. A classic example from the bioenergy literature involves the assumption that European domestic wastes would degrade to methane in landfill sites if they were not otherwise burnt (for example JEC (2007)). Depending on the specifics, this may or may not be the case, but making the assumption results in the use of that feedstock for bioenergy looking considerably better than if it is ignored.

\section{Specific Baseline and Boundary issues}

\subsection{Capital goods}

The inclusion of capital goods in LCA is complicated. They are not 'used up', or only marginally so, in the production of the functional unit (for example land and machinery respectively). They can contain considerable embodied resources, but to allocate fractions of them to each functional unit is difficult, due to lack of clarity about what the fractions should be - affected for example by the often unknown life-span of the machinery. For these reasons, PAS2050 concludes " $(\mathrm{t})$ he manufacturing of production equipment, buildings and other capital goods shall not be included"(BSI, 2008) while in contrast ISO 14040 advises that capital goods should be included (ISO, 2006).

How would the inclusion or exclusion of capital goods influence the results of our project? As this research goes beyond evaluating the environmental implications of rice production, the use of capital is vital for its socio-economic questions, so it will be included. But if the analysis is confined to environmental dimensions, what conditions make embodied emissions vital to include?

Nemecek (2005) (quoted in Frischknecht et al. (2007)) reviewed the role of capital goods in LCA, and found that in agricultural LCAs, capital goods contribute $20 \%$ of fossil fuel demand in intensive production and significantly more in organic practices. The higher percentage for organic production arises because while machinery use is similar, the lack of synthetic 
fertiliser use significantly reduces the total fossil fuel demand, increasing the relative importance of the (approximately) constant capital goods.

Although the details of the research generating the results discussed above are not reported, it is likely that most agricultural LCAs relate to highly mechanised, intensive production conditions. Data from Indian rice production may be very different, owing to far greater reliance on labour than on capital.

\subsection{Emission factors}

Often, once the initial boundaries of an LCA have been drawn, too much information must be gathered for effective work to be possible. For example most rice production uses urea fertiliser, so a full LCA for rice would include the emission flows emanating from the production of urea - similarly for other fertilisers, pesticides and all machinery, for the bullock feed and for the plastic in the electric plug connecting the irrigation pump to the electricity... A full LCA of rice would include LCAs for almost all the products in the world. In addition eternal loops are generated, for example the production of steel requires coal, the extraction of which requires steel, the production of which requires coal etc.

Emission factors are essential for resolving both of these problems. Emission factors are figures from previous studies that provide an off-the-shelf figure. For example work by the Centre for Science and Environment found that the production of urea in India requires an average of $0.7 \mathrm{kgCO}_{2}$-eq urea $\mathrm{kg}^{-1}$, thereby providing an off the shelf carbon emission factor for urea fertiliser (Centre for Science and Environment, 2009). We do not have to generate our own.

To use published emission factors greatly reduces field effort and costs, but emission factors should be treated with caution. Say that data from a German urea factory ere the sole source, could it still be used as a proxy for urea production in Indian conditions? German urea factories could be newer, with more environmentally efficient technology than in Indian factories. In which case the German figure would provide an under estimate of emissions associated with urea use. Alternatively higher environmental standards in Germany may require scrubbers that reduce the efficiency of urea produced in Germany compared to that in India - in which case German figures would over-estimate emissions associated with Indian urea production.

Thus while emission factors are essential aids to research, they should be used with care. Questions that should be asked routinely are: first, are these data reliable? If the LCA that carried them out was poorly designed and implemented, then the figure will be of little value. Second, are they representative? The German urea factory is an example of production that may not be representative. Third, if they fail these tests, do any other data exist? This is a tricky but common situation to encounter when building an LCA. Even if the emissions factors are neither reliable nor representative, they may have to be used, due to lack of alternative data. If data is un-representative, it may be possible to apply a correcting factor for the data. For example if a soil process rate (such as organic matter decomposition) 
is transferred from European research conditions to Indian soils, then applying a q10 of 2, and doubling the result, may be justified.

With emission factors, as will all aspects of LCAs, all assumptions should be clearly stated, including judgements on the reliability or representativity of imported data. Finally the importance of data for each parameter should be demonstrated using sensitivity analyses.

\subsection{Allocation problems}

The concepts of baselines and boundaries can be developed to address further questions: are co-products included within the boundaries of the LCA, and if so, with what baseline are they to be compared?

It is rare that only one product is produced along a supply chain. For example rice production produces rice, straw, husk and bran - while the 'primary driver' of this set of commodities is rice. What share of the GHG burden of rice production should be allocated to each co-product?

\subsubsection{Potential methods of allocation}

Mass Balance. This is a tempting solution because it is relatively easy to use, but it often bares little relationship to the energy content / environmental burden of a product, or the 'primary driver' behind, or reason for, the production of a set of products and bye-products. A simple example is the production of biodiesel from oilseed rape. For each tonne of biodiesel, $>4$ t of co-products are produced. Allocation by mass would inaccurately suggest that biodiesel - the primary driver for production in this case - is only responsible for $20 \%$ of the total emissions.

Energy allocation (used in the EU RED (Renewable Energy Directive)). This has similar problems to allocation by mass balance, and, unless all the co-products are destined for energy generation, it may not reflect their roles in driving the production process. For example DDGS (dried distillers grains with solubles; the typically protein-rich solid residue from ethanol production) or from rape meal (the solid residue from oil-seed rape/canola after the oil has been removed) is typically used for animal feed, so measuring its energy value either to the end-user or as a driver for the original crop bears little relation to reality.

Substitution (expanding the boundary). A further option is to expand the boundary to include the final destinations for the co-products. This is preferred by many LCA practitioners. It has two major problems, discussed by Kindred et al , 2008: first, how to choose the product to displace, and second, how to know whether the GHG emissions are actually 'avoided'. The first problem is very real and also self-explanatory. The second is more complicated. An example given by Kindred et al is the use of rape meal (the coproduct of rape biodiesel) substituting for soy meal (a key feed in UK livestock rations). Soy meal is itself a by-product of soy-oil production. If the rape meal substitutes the soy meal then all the allocation for soy production must be allocated to the soy oil, so although the 
oilseed rape biodiesel has a lower apparent GHG burden due to soy substitution, in reality there has been no change in emissions.

\section{Price mechanisms}

Allocation by price is often perceived as the most realistic and practical means of addressing co-products, but it involves the assumption that market prices accurately reflect and drive changes in the real world. In rural India, price allocation may provide a flawed reflection of reality due to market failures, seasonality, and the 'field economy' where people do not behave as micro-economics predicts. Kindred et al (2008) recommend that shadow prices 'based on careful evaluation, should be adopted for any products and services that are not traded outside the process(es) under consideration'.

\section{Co-products versus bye-products versus waste}

Waste is defined by ISO 14044 and PAS 2050:2011 as "substances or objects which the holder intends or is required to dispose of". It is important to differentiate between i) those wastes that can be given away (for example some ashes from a rice mill) ii) those that incur a cost on disposal such as contaminated waste that should have further treatment before final disposal, or iii) those that incur a cost just through transport.

The implication of being a waste is that if any use for it is found, then it will have a zero carbon history. This can make a dramatic difference to the embodied GHG of a product. For example if the embodied GHG of biodiesel made from old chip oil is compared with dedicated vegetable oil, the embodied emissions are dramatically lower from the chip oil, as, classified as a waste, it brings no embodied GHG to the biodiesel.

The guiding principle and ultimate test of any allocation procedure is that it should accurately reflect changes that actually happen or are likely to happen in the real world (Kindred et al., 2008).

\subsection{Indirect effects. Indirect land use change}

Indirect land use change (ILUC) occurs when a change in land use in one area leads, via a market response, to a land use change elsewhere. A change in production practices on an Indian farm can indirectly drive land use change many thousands of miles away. For example if there were a dramatic shift to lower yielding varieties throughout Tamil Nadu, then the local supply of rice will decrease while demand stays constant. This is likely to increases the demand for rice or for rice-substitutes from other crops and regions, and subsequently the price will rise. The global agricultural market compensates for this increased price through three mechanisms: reduced consumption, increased intensification, and expansion of the global area down to these crops. While the intensification of production on long-cultivated agricultural land can result in important increases in GHG 
emissions it is the final factor that can lead to the most dramatic increases in emissions of GHGs. Depending on the habitat into which agriculture expands LUC emissions can range from less than 2 to greater than 500 tCO2 ha-1 (IPCC, 2006b). ILUC figures used in the literature include 351t CO2-eq ha-1 (Searchinger et al., 2008), 400t CO2-eq ha-1 (Fritsche et al., 2009) and 385t CO2 ha-1 from Burney et al (2010). The Gallagher Review gives a useful analysis of this debate (Gallagher, 2008). Interestingly it is common for ILUC to be ignored when discussing agricultural sustainability, for example Pretty (2008).

The provision of estimates for ILUC from changing rice production is both difficult and debated, and will not be covered here since the literature mentioned above deals with the issues. But the potential for dramatic, offsite increases in GHG emissions from reduced production is significant, as is the potential for ILUC credits if rice yields increase and so reduce the pressure for further expansion at the agricultural land margins.

This section has massively simplified a very complicated set of interactions which it is tempting to ignore, while setting the boundary simply around the field of rice to be researched. But the latter would risk ignoring a source of emissions/mitigation that might dwarf all other steps in the rice production process. For this reason it is best to expand the boundary to include ILUC, while accepting that there are many uncertainties as to how it is best included.

\section{Further indirect effects}

Changes in the supply and demand of rice inputs and co-products can also have indirect effects. For example, rice straw power station projects have been proposed under the Clean Development Mechanism. At present rice straw is either returned to the field, used as animal fodder, or used for domestic fuel consumption. If demand and rewards are high enough, significant quantities of straw could be used for electricity generation, potentially providing low carbon electricity. But if this were to occur then previous end uses would have to find alternatives, and these should also be included within the LCA.

A further class of indirect effects is composed of those that are not produced from the field, but are directly due to action on that field, of which $\mathrm{N}_{2} \mathrm{O}$ emissions are the prime example. $\mathrm{N}_{2} \mathrm{O}$ is emitted by bacteria in the nitrogen cycle, but the increased quantities of active (as opposed to atmospheric) nitrogen increases the $\mathrm{N}_{2} \mathrm{O}$ released. This is recognised by LCA practitioners, who use an emission factor from the IPCC, typically $1.25 \%$ of applied N, to cover both on and off field $\mathrm{N}_{2} \mathrm{O}$ emissions. In an elegant paper Crutzen (2007) worked backwards from the total quantity of atmospheric $\mathrm{N}_{2} \mathrm{O}$ and suggested that this figure should be up to $3 x$ higher, as $\mathrm{N}_{2} \mathrm{O}$ was released from waterways and other off-site locations needing to be attributed to the original $\mathrm{N}$ application. This is especially important to intensive HYV rice, as, due to the predominantly flooded, anaerobic soils, little $\mathrm{N}_{2} \mathrm{O}$ is released directly on site. But, with a nitrogen use efficiency of around 31\% (Cassman et al., 2002), significant quantities of $\mathrm{N}$ are lost, often with surface water, and presumably results in indirect $\mathrm{N}_{2} \mathrm{O}$ emissions. 


\section{Rebound effects.}

The increased efficiency of resource use, for example water used for SRI compared with water for intensive high yielding varieties, can sometimes have counter-intuitive implications. For example the introduction of a more efficient diesel irrigation pump (pumping more water with less diesel) is tempting to treat as generating a diesel savings too. But, the impact may be less clear on the ground. It is possible that the reduced cost of running the pump could encourage the farmer to use more water than $s /$ he otherwise would have done, thereby reducing the efficiency savings. If it encourages even more diesel use than before the efficient replacement, it may even tip the balance of costs for the farm production unit in the aggregate. A good review of the rebound effect can be found in Sorrell (2007).

\section{The Materiality of Rice project}

The decisions on baselines and boundaries for the farming stage of the research project om the materiality of rice are discussed in detail in the individual working papers. In brief, we used a constant baseline of irrigated, intensive ('green revolution') rice production to reflect the major technology for rice in India. With the objective of understanding the environmental, economic and social characteristics of different forms of rice production, Figure 2 presents the 12 metrics included within the boundaries. This selection reflected both the methodology ${ }^{4}$ and the breadth of the objective. Comparing Figure 2 with Figure 1, this project used a simplified model of the real rice production system, but developed a model that combined workability, meaningful disciplinary breadth, and transparent explanations of what was not included, so that the gaps are apparent for further research.

\begin{tabular}{|c|c|}
\hline Metrics used & Processes measured \\
\hline Non-fossil energy & \multirow{16}{*}{$\begin{array}{l}\text { Seed } \\
\text { Seedbed creation } \\
\text { Bund } \\
\text { Cultivation } \\
\text { Transplanting } \\
\text { Weeding } \\
\text { Synthetic fertiliser } \\
\text { Pesticides (synthetic or 'natural') } \\
\text { Manure } \\
\text { Irrigation } \\
\text { Soil derived } \mathrm{CH}_{4}^{*} \\
\text { Soil derived } \mathrm{N}_{2} \mathrm{O}^{*} \\
\text { Harvest } \\
\text { ILUC } \\
\text { SOC storage } \\
\text { Sale } \\
\text { Loans and insurance costs }\end{array}$} \\
\hline Fossil energy (including embodied) & \\
\hline Ground water & \\
\hline GHG emissions (including embodied) & \\
\hline Labour costs & \\
\hline Capital costs & \\
\hline Derived costs & \\
\hline Income & \\
\hline Labour quantity & \\
\hline Labour type (family, casual) & \\
\hline Labour type (gender) & \\
\hline Labour quality (pay per hour/day) & \\
\hline Derived metrics used & \\
\hline Cost of carbon & \\
\hline Costs of family labour & \\
\hline Cost of electricity & \\
\hline
\end{tabular}

\begin{tabular}{|l|}
\hline Metrics excluded. \\
\hline Embodied water \\
Rain water \\
Embodied labour \\
Embodied human and animal \\
energy \\
Fixed capital goods (land, \\
houses, buildings) \\
Minor capital goods (hand \\
tools \\
\hline
\end{tabular}

Figure 2. System boundaries, and metrics used in analysis. Processes marked with an * have no labour and optionally no economic metrics associated with them. Those marked with an ${ }^{+}$have no social or environmental metrics associated with them.

\footnotetext{
${ }^{4}$ We used recall surveys so could not use metrics that relied on time-based data collection.
} 


\section{Conclusion}

Life cycle assessment is a very powerful tool, but may be used either well or badly. This paper has aimed to show a range of areas that need consideration when building or reading a LCA, in order to allow them to be built and read in a more robust fashion. A well designed LCA can enhance environmental understanding and push policy in useful directions, but a bad LCA can do the exact opposite.

So, use it, but to do it well, every step needs explanation and justification. And other LCAs need a critical approach to their reading and interpretation.

\section{Acknowledgements}

With thanks for funding to the ESRC/DfID Joint Scheme award RES-167-25-MTRUYG0; ES/1033768/1. The views expressed are those of the author.

\section{References}

BSI, (2008) PAS 2050. Specification for the assessment of the life cycle greenhouse gas emissions of goods and services, in: Institution, B.S. (Ed.), Available at http://www.bsigroup.com/en/Standardsand-Publications/Industry-Sectors/Energy/PAS-2050/

Cassman, K.G., Dobermann, A., Walters, D.T. (2002) Agroecosystems, nitrogen-use efficiency, and nitrogen management. AMBIO: A Journal of the Human Environment 31, 132-140.

Centre for Science and Environment, (2009) Green Rating Project, Fertilizers, . http://www.cseindia.org/userfiles/79-90\%20Fertilizer\%281\%29.pdf, New Delhi.

Crutzen, P.J., Mosier, A.R., Smith, K.A., Winiwarter, W. (2007) N2O release from agro-biofuel production negates global warming reduction by replacing fossil fuels. Atmospheric Chemistry Physical Discussions, 11191-11205.

Espinosa, N., Garcia-Valverde, R., Krebs, F.C. (2011) Life-cycle analysis of product integrated polymer solar cells. Energy \& Environmental Science 4.

Frischknecht, R., Althaus, H.-J., Bauer, C., Doka, G., Heck, T., Jungbluth, N., Kellenberger, D., Nemecek, T. (2007) The Environmental Relevance of Capital Goods in Life Cycle Assessments of Products and Services. International Journal of Life Cycle Assessment.

Gallagher, E., (2008) The Gallagher review of the indirect effects of biofuels production, in:

Department for Transport (Ed.). Renewable Fuels Agency.

Gathorne-Hardy, A., (2013) Life cycle assessment of four rice production systems: High Yielding Varieties, Rainfed, System of Rice Intensification and Organic, in: Harriss-White, B. (Ed.), Technology, Jobs and A Lower Carbon Future: Methods, Substance and Ideas for the Informal Economy

(The case of rice in India) New Delhi.

Gathorne-Hardy, A., Harriss-White, B., (2013) Embodied emissions and dis-embodied jobs: the environmental, social and economic implications of the rice production-supply chain in SE India. , Symposium on Technology, Jobs and a Lower Carbon Future :Methods, substance and ideas for the informal economy (the case of rice in India). IHD, New Delhi.

IEA, (2012) Understanding Energy Challenges in India Policies, Players and Issues Partner Country Series. International Energy Agency, France. 
ISO, (2006) Environment Management - Life Cycle Assessment - Principles and Framework. EN ISO 14040, in: International Organization for Standardization (ISO) (Ed.), Switzerland.

JEC, (2007) JRC / EICAR / CONCAWE Well to Wheels analysis of future automotive fuels and powertrain in the European Context, WELL TO TANK report version 2c. JEC,

http://www.co2star.eu/publications/Well to Tank Report EU.pdf.

Kindred, D., Mortimer, N., Sylvester-Bradley, R., Brown, G., Woods, J., (2008) Understanding and managing uncertainties to improve biofuel GHG emissions calculations, HGCA Project No. MD-06070033. HGCA London.

Merrild, H., Damgaard, A., Christensen, T.H. (2008) Life cycle assessment of waste paper management: The importance of technology data and system boundaries in assessing recycling and incineration. Resources, Conservation and Recycling 52, 1391-1398.

PAS 2050:2011, (2011) Specification for the assessment of the life cycle greenhouse gas emissions of goods and services. BSI, London.

RSPB, (2011) Bionenergy: a burning issue,

http://www.rspb.org.uk/Images/Bioenergy a burning issue 1 tcm9-288702.pdf.

Searchinger, T., Heimlich, R., Houghton, R.A., Dong, F., Elobeid, A., Fabiosa, J., Tokgoz, S., Hayes, D., Yu, T.-H. (2008) Use of U.S. Croplands for Biofuels Increases Greenhouse Gases Through Emissions from Land-Use Change. Science 319, 1238-1240.

Sorrell, S., (2007) The Rebound Effect: an assessment of the evidence for economy-wide energy savings from improved energy efficiency, Technology and Policy Assessment. UK Energy Research Centre, London.

Suh, S., Lenzen, M., Treloar, G.J., Hondo, H., Horvath, A., Huppes, G., Jolliet, O., Klann, U., Krewitt, W., Moriguchi, Y., Munksgaard, J., Norris, G. (2004) System boundary selection in life-cycle inventories using hybrid approaches. Environmental Science \& Technology 38, 657-664. 